\title{
Práticas de Monitoramento Cognitivo em Atividades de Modelagem Matemática
}

\section{Cognitive Monitoring Practices in Mathematical Modeling Activities}

\author{
Rodolfo Eduardo Vertuan* \\ Lourdes Maria Werle de Almeida* ${ }^{* *}$
}

\begin{abstract}
Resumo
O presente artigo refere-se a uma pesquisa cujo objetivo é identificar, nas manifestações de estudantes enquanto desenvolvem atividades de Modelagem Matemática, as formas de monitoramento cognitivo, bem como caracterizar elementos das atividades de Modelagem que promovem esse monitoramento dos alunos. Os dados analisados consistem em falas dos alunos gravadas no decorrer do desenvolvimento das atividades, nos registros produzidos para as resoluções e nas anotações do diário de campo do pesquisador. O que se pode concluir é que, em Modelagem Matemática as práticas de monitoramento são realizadas coletivamente, aprendidas nas interações entre os diferentes envolvidos com as atividades e suscitadas pelo que, nesse artigo, chamamos unicidade das atividades de Modelagem, a qual refere-se à prática constante de analisar o desenvolvimento da atividade, considerando-a em sua totalidade.
\end{abstract}

Palavras-chave: Metacognição. Monitoramento Cognitivo. Modelagem Matemática. Educação Matemática.

\begin{abstract}
This article refers to a research that aims to identify, about student manifestations while developing Mathematical Modeling activities, forms of cognitive monitoring and characterizing elements of Modeling activities that promote this monitoring of students. The data analyzed consist of students speeches saved into audio during the development of activities, of the produced records to do the resolutions and of the researcher's field diary notes. What can be concluded is that in Mathematical Modeling the monitoring practices are held collectively, are learned in the interactions among the different things involved with the activities and raised by them, in this article, we named as uniqueness of modeling activities, which refers to the constant practice of analyzing the development of the activity, considering it in its totality.
\end{abstract}

Keywords: Metacognition. Cognitive Monitoring. Mathematical Modeling. Mathematics Education.

\section{Introdução}

Ao implementar atividades de Modelagem Matemática nas aulas temos nos interessado, de modo particular, pela tomada de consciência dos alunos quanto às suas

\footnotetext{
" Doutor em Ensino de Ciências e Educação Matemática pela Universidade Estadual de Londrina (UEL). Docente da Universidade Tecnológica Federal do Paraná (UTFPR), Toledo/PR, Brasil. Endereço para correspondência: Rua Cristo Rei, 19, Vila Becker, Toledo/PR, Brasil, CEP: 85902-490. E-mail: rodolfovertuan@yahoo.edu.br

** Doutora em Engenharia de Produção pela Universidade Federal de Santa Catarina (UFSC). Docente da Universidade Estadual de Londrina (UEL), Londrina/PR, Brasil. Endereço para correspondência: Rua Antônio Pisicchio, 155, apto 303, CEP: 86050-482, Londrina/PR, Brasil. E-mail: lourdes.maria@ sercomtel.com.br
} 
práticas de resolução e à utilização dessa consciência de modo a potencializar a aprendizagem e a realização de novas atividades de Modelagem ${ }^{1}$. Em outros termos, temos nos interessado por investigar as práticas de monitoramento cognitivo que os alunos põem em ação quando desenvolvem esse tipo de atividade.

Para isso, concebemos o monitoramento cognitivo como um constructo coletivo, histórico, social e cultural e tomamos as atividades de Modelagem Matemática como aquelas nas quais o monitoramento pode emergir do trabalho em grupo propiciado por elas.

Diante do exposto, apresentamos nesse trabalho os principais resultados de uma investigação que tinha como objetivo identificar as formas de monitoramento cognitivo expressas pelos alunos durante a realização de atividades de Modelagem Matemática e caracterizar elementos das atividades de Modelagem que promoveram esse monitoramento.

Nesse contexto, estruturamos o presente artigo apresentando, inicialmente, aspectos da Modelagem Matemática. Em seguida, discutimos aspectos do monitoramento cognitivo segundo a vertente processual da Metacognição (FLAVELL; WELLMAN, 1977; TOVARGÁLVEZ, 2008). Os encaminhamentos metodológicos e a caracterização dos sujeitos participantes da pesquisa são apresentados na sequência. Finalmente, realizamos a descrição de Episódios ${ }^{2}$ significativos diante dos objetivos desse artigo, bem como realizamos as análises dos mesmos à luz da fundamentação teórica.

\section{Acerca da Modelagem Matemática}

Segundo D'Amore (2007, p. 287) as atividades desenvolvidas nas aulas de Matemática deveriam tratar “[...] de uma situação problemática e não de um problema: o aluno encontra-se diante de um problema no interior de uma atividade mais ampla".

É com esta perspectiva de mediar as aulas por situações-problema que pensamos as atividades de Modelagem Matemática. Segundo Almeida, Silva e Vertuan (2012), uma

\footnotetext{
[...] atividade de Modelagem Matemática pode ser descrita em termos de uma situação inicial (problemática), de uma situação final desejada (que representa uma solução para a situação inicial) e de um conjunto de procedimentos e conceitos necessários para passar da situação inicial para a situação final. [...] $\mathrm{O}$ termo "problema" é entendido aqui como uma situação na qual o indivíduo não possui esquemas a priori para sua solução. Assim, para a resolução de situações problema, de modo geral, não há procedimentos previamente conhecidos ou soluções já indicadas (ALMEIDA, SILVA, VERTUAN, 2012, p.12).
}

\footnotetext{
${ }^{1}$ Nesse trabalho, as expressões Modelagem e Modelagem Matemática são entendidas como sinônimas.

2 Denominamos episódios alguns dos momentos da resolução em que as discussões dos alunos os levaram a tomar decisões em relação ao encaminhamento da atividade.
} 
À situação final desejada a que se referem os autores está associado um modelo matemático. Este, por sua vez, segundo Bean (2012, p. 5) é uma “[...] construção simbólica expressa principalmente na linguagem matemática, que se refere a algumas relações consideradas pertinentes a uma situação, de modo que auxilie na interpretação, compreensão e/ou tomada de decisão concernentes a tal situação e em outras situações, nas quais se considere adequado aplicar o modelo". Em sala de aula, construir modelos matemáticos e utilizá-los para o entendimento de situações extra matemáticas implica em considerar a Modelagem como alternativa pedagógica para o ensino e a aprendizagem da Matemática.

As ações dos alunos nas atividades de Modelagem estão associadas ao que Almeida, Silva e Vertuan (2012) chamam fases da Modelagem e consistem em: inteiração, matematização, resolução, interpretação de resultados e validação. A ordem em que tais fases aparecem bem como o tempo dedicado a cada uma e os obstáculos presentes em cada uma delas dependem da dinâmica da atividade e do contexto em que a atividade é realizada. É comum e adequado, por exemplo, que as fases sejam revisitadas sempre que necessário, de modo que o desenvolvimento da atividade de Modelagem seja monitorado pelos alunos de acordo com os planos de ação estabelecidos e validados passo a passo.

Os autores associam a inteiração com o ato de inteirar-se, informar-se sobre. A inteiração acontece a partir da escolha de um tema a investigar. O tema escolhido é, geralmente, conhecido em alguns aspectos pelos alunos e, muitas vezes, dele surge também uma questão a investigar. Essa questão, por sua vez, só ganha status de questão a investigar quando os alunos buscam inteirar-se do tema selecionado. É possível que, ao conhecer melhor o tema, o problema inicial deixe de existir e outros tomem o seu lugar. Nesse sentido,

[...] ainda que seja uma fase inicial, a inteiração pode se estender durante o desenvolvimento da atividade, considerando que a necessidade de novas informações pode emergir no decorrer do desenvolvimento da atividade de Modelagem (ALMEIDA, SILVA, VERTUAN, 2012, p.16).

O entendimento da situação inicial, a interpretação de fatos e informações, o agrupamento de ideias são ações cognitivas presentes na fase inteiração. Essas ações, segundo Bloom et al $\left(1956^{3}\right.$, apud FERRAZ; BELHOT, 2010) correspondem a um segundo estágio da construção do conhecimento e são relacionadas ao que denominamos compreensão da situação. Já a identificação de um problema, a elaboração de uma questão e a definição de metas para a sua resolução são ações que denominamos de estruturação da situação.

A partir da inteiração em relação à situação, da obtenção de informações qualitativas e quantitativas e da elaboração de uma questão a investigar via Matemática, os estudantes

\footnotetext{
${ }^{3}$ BLOOM, B.S. et al. Taxonomy of educational objectives. New York: David Mckay, 1956. 262p. (v.1)
} 
passam, geralmente, à fase de matematização. A matematização pode ser caracterizada em termos de transição de linguagem, uma vez que os resultados obtidos na fase de inteiração são, em sua maioria, expressos em linguagem natural e não possuem uma linguagem matemática diretamente associada, mas que precisa ser elaborada.

As descrições matemáticas são realizadas via formulação de hipóteses, seleção de variáveis e simplificações das informações. Tais processos, no entanto, não implicam em considerar apenas um recorte da situação inicial, mas considerar o quê dessa situação influencia fortemente o problema investigado e, portanto, importa para a solução da questão elaborada. Isso remete à importância de se selecionar variáveis, formular hipóteses e simplificar informações de modo a construir uma realidade que, segundo Cifuentes e Negrelli (2011) não coincide exatamente com a primeira, mas ainda é uma boa representação dela.

A matematização é, assim, realizada diante dos conhecimentos prévios dos sujeitos em relação à situação inicial, em relação às experiências anteriores na condição de modeladores e em relação à Matemática utilizada para a investigação da questão. Nesse sentido, a ação cognitiva que também denominamos matematização (ALMEIDA, SILVA E VERTUAN, 2012) corresponde à transição da linguagem natural em que o problema é dado para uma linguagem matemática que evidencia o problema matemático a ser resolvido.

$\mathrm{Na}$ fase resolução os alunos constroem um modelo matemático da situação inicial, modelo esse que abarca características do fenômeno e permite interpretá-lo, responder à questão inicial e, em alguns casos, até mesmo, realizar previsões para o problema em estudo. Nessa fase o sujeito utiliza conceitos, métodos e representações matemáticas, põe em uso seus conhecimentos prévios, busca padrões, recorre a ferramentas computacionais, coordena diferentes representações dos objetos matemáticos, busca conhecer conceitos novos e ressignifica os já conhecidos, de modo que, nessa fase, com base na caracterização proposta por Bloom (1956, apud FERRAZ; BELHOT, 2010), identificamos a ação cognitiva síntese.

Analisar as respostas obtidas diante da situação investigada é ação das fases interpretação de resultados e validação. Essas fases visam avaliar a representação matemática associada ao problema e a resposta obtida.

Caso o grupo de alunos que investiga a situação entenda que a resposta é satisfatória, os alunos comunicam a resposta do problema para os outros alunos de modo a convencê-los de que a solução apresentada é consistente. Segundo Brown e Edwards (2011, p.187, tradução nossa), “[...] a comunicação dos alunos acerca de suas soluções para atividades de modelagem, dá uma visão da profundidade de suas compreensões matemáticas e como eles utilizam o conhecimento prévio do contexto de uma atividade na sua solução" - o que 
constitui um importante espaço de avaliação das atividades de Modelagem e das compreensões dos alunos. Caso o grupo de alunos entenda que a resposta obtida para o problema não é satisfatória, novas informações precisam ser pesquisadas, reestruturações nas hipóteses passam a ser realizadas e o processo inicia-se novamente. Todavia, em Modelagem,

[...] um resultado que poderia ser considerado errado não equivale naturalmente a uma nota baixa, a um risco com caneta vermelha. Vale sim, como um resultado testado, rejeitado e que pode indicar novos caminhos e estratégias, novas necessidades e rumos. Erros assim levam, muitas vezes, a uma nova compreensão do problema original e também do modelo matemático (MEYER, CALDEIRA e MALHEIROS, 2011, p.58).

Nesse contexto de desenvolvimento de uma atividade de Modelagem e diante da perspectiva de que a Modelagem tem nos trabalhos em grupo o seu aporte maior é que consideramos que, em sala de aula, os grupos de alunos desenvolvem as atividades, orientados e estimulados pelo professor, de tal modo que quanto maior a familiarização dos alunos com atividades de Modelagem Matemática, menor é a interferência do professor no que se refere à indicação de procedimentos durante o desenvolvimento da atividade.

A familiarização dos alunos com atividades de Modelagem pode resultar, para além de uma compreensão acerca do que constitui uma atividade de Modelagem, em um aumento no repertório de estratégias de resolução e em certa autonomia frente à utilização dos conceitos matemáticos, suas propriedades e sua importância no contexto do problema.

Assim, quando um aluno toma consciência dos conceitos matemáticos que conhece, das estratégias que pode utilizar frente a um problema específico e dos modos como se dá sua aprendizagem, pode otimizar suas ações de modo a potencializar a apreensão de conhecimentos e o desenvolvimento cognitivo. Ao conhecimento relativo à cognição e às práticas de monitoramento cognitivo, dá-se o nome de metacognição. A opção, nesse texto, pela metacognição, vem ao encontro do que expressa Anastácio (1990) quando afirma que

[...] não é suficiente conhecer os passos na construção, análise e interpretação de um modelo matemático e suas diferentes aplicações. Faz-se necessário desenvolver nos alunos a capacidade de avaliar o processo de construção do modelo e os diferentes contextos de aplicação dos mesmos (ANASTÁCIO, 1990, p.97).

\section{Acerca do Monitoramento Cognitivo - vertente processual da Metacognição}

De acordo com González (2009), na realização de uma atividade aspectos cognitivos, afetivos e metacognitivos podem ser mobilizados, sendo que:

Os aspectos cognitivos referem-se aos processos, habilidades, estratégias que facilitam o manejo da informação [...]. Os aspectos afetivos referem-se às atitudes, emoções e crenças, tanto acerca de si mesmo, como em relação à disciplina e às demais pessoas. Os aspectos metacognitivos remetem à capacidade que têm os seres 
humanos de estarem conscientes de sua própria atividade cognitiva, concorrentemente com a realização de alguma tarefa intelectualmente exigente ${ }^{4}$ (GONZÁLEZ, 2009, p.132-133, tradução nossa).

A metacognição pode ser entendida, neste contexto, como uma reflexão de segundo nível, no sentido de ser uma operação mental que o sujeito realiza ao elaborar conhecimentos sobre a sua própria maneira de construir conhecimentos. Nesse contexto, a metacognição pode ser entendida como uma atividade mental na qual outros processos mentais constituemse objetos de reflexão e análise do próprio sujeito.

Segundo Flavell (1976), precursor do uso do termo metacognição, ela consiste:

[...] no conhecimento que uma pessoa tem acerca dos próprios processos e produtos cognitivos ou qualquer outro assunto relacionado à eles, por exemplo, o aprendizado das propriedades relevantes da informação ou dos dados. Assim, pratico a metacognição [...] quando me dou conta de que tenho mais dificuldades em aprender A que B; quando compreendo que devo verificar pela segunda vez $\mathrm{C}$ antes de aceitálo como feito; quando me ocorre que seria bom examinar todas e cada uma das alternativas de uma questão de múltipla escolha antes de decidir qual a melhor, quando resolvo tomar nota de D porque posso esquecê-lo. [...] A metacognição refere-se, entre outras coisas, ao monitoramento ativo e à consequente regulação e orquestração desses processos em relação aos objetos cognitivos ou dados sobre os quais eles incidem, normalmente, à serviço de alguma meta ou objetivo concreto (FLAVELL, 1976, p.232, tradução nossa).

A metacognição pode ser tomada, portanto, como produto ou como processo. Como "produto" quando se refere ao conhecimento acerca da cognição, ou seja, ao conhecimento que as pessoas têm sobre quando, onde, por que e como utilizar os conhecimentos que possuem, sua utilidade e eficácia. Como "processo" quando se relaciona ao monitoramento que um sujeito exerce sobre sua própria atividade cognitiva, quando se refere às faculdades de planificar, de dirigir à compreensão e de avaliar o que foi aprendido.

Neste sentido, o monitoramento cognitivo (FLAVELL, 1976; TOVAR-GÁLVEZ, 2008; LANZ, 2006; COHORS-FRESENBORG, 2010; DOLY, 1999) refere-se ao acompanhamento que um sujeito faz do próprio processo cognitivo quando realiza uma tarefa, no sentido de gerir esse processo, desde o planejamento de ações e estabelecimento de metas até o seu alcance. Segundo González (1998),

[...] realizar uma ação metacognitiva consiste em converter a própria atividade cognitiva em um objeto sobre o qual se exerce algum tipo de ação cognitiva: monitorar (ou seja, supervisionar, analisar, revisar, modificar) e controlar (ou seja, dirigir, manter sobre o domínio); essas ações podem ocorrer concorrentemente com o desenvolvimento da atividade (interrogatório autorreflexivo) ou de modo retrospectivo (recordação estimulada) (GONZÁLEZ, 1998, p.64, tradução nossa).

\footnotetext{
${ }^{4}$ Para González (2009, p.134, tradução nossa) as tarefas intelectualmente exigentes “[...] são aquelas atividades que propiciam o esforço de raciocínio; ou seja, não são realizadas com o mero exercício de memorizações, com a utilização mecânica de esquemas algorítmicos, nem com a aplicação de receitas pré-concebidas; ao contrário, devem merecer a realização de certo esforço intelectual e, além disso, requerer o exercício de variadas habilidades cognitivas básicas".
} 
Segundo Flavell (1979), o monitoramento cognitivo acontece pela ação e interação entre quatro classes de fenômenos: conhecimento metacognitivo (ou conhecimento acerca da cognição), experiências metacognitivas, objetivos cognitivos e ações cognitivas. Para o autor:

O conhecimento metacognitivo é aquele segmento de seus conhecimentos de mundo armazenados (quando criança ou adulto), que tem feito as pessoas serem criaturas cognitivas, com suas diversas tarefas, objetivos, ações e experiências. [...] As experiências metacognitivas são quaisquer experiências cognitivas ou afetivas, que acompanham ou pertencem a qualquer empreendimento intelectual. [...] Objetivos (ou tarefas) referem-se aos objetivos de um empreendimento cognitivo. Ações (ou estratégias) referem-se às cognições ou outros comportamentos utilizados para consegui-las (FLAVELL, 1979, p.906-907, tradução nossa).

Tovar-Gálvez (2008), também considerando a metacognição numa perspectiva processual, a define como uma estratégia que abarca três dimensões, por meio das quais o sujeito atua e desenvolve as atividades:

a) dimensão de reflexão, na qual o sujeito reconhece e avalia suas próprias estruturas cognitivas, possibilidades metodológicas, processos, habilidades e desvantagens; b) dimensão de administração durante a qual o indivíduo, já consciente de seus estados, procede a conjugar esses componentes cognitivos diagnosticados com o objetivo de formular estratégias para dar solução à tarefa; e c) dimensão de avaliação, através da qual o sujeito valida a implementação de suas estratégias e o grau em que se está alcançando o objetivo cognitivo. [...] através de uma estratégia metacognitiva, o sujeito constrói ferramentas para dirigir suas aprendizagens e, por último, adquirir autonomia (TOVAR-GÁLVEZ, 2008, p.3).

Embora o autor refira-se à dimensão de reflexão como de incumbência do docente ao selecionar instrumentos ou atividades que permitam valorizar os conhecimentos prévios dos estudantes e que se relacionam com a solução do problema, reconhecemos que ela também diz respeito às atividades dos alunos, que tomam para si a resolução do problema e buscam avaliar sua própria estrutura cognitiva como ponto de partida e como condição para poder pensar sobre o problema. A administração, por sua vez, ocorre baseada no planejamento de ações e com vistas a cumprir um objetivo cognitivo, e consiste nas estratégias e nas decisões tomadas pelo sujeito no decorrer da atividade. Finalmente, a dimensão de avaliação

[...] implica na definição de critérios que permitam determinar se o objetivo cognitivo está sendo alcançado, se se está chegando à resolução do problema, se a metodologia proposta e as atividades planejadas estão indo ao encontro do planejado; significa estabelecer um sistema para regular a execução de estratégias (TOVAR-GÁLVEZ, 2008, p.5).

Embora caracterizadas isoladamente, essas dimensões se combinam e atuam durante todo o desenvolvimento da atividade, apresentando caráter dinâmico. Para Grangeat (1999),

[...] é conveniente instaurar, na aula, momentos durante os quais os alunos precisam refletir os processos intelectuais que puseram em ação no curso de atividades em cuja resolução obtiveram êxito. Tal reflexão pode conduzi-los progressivamente a identificar as estratégias mentais realmente utilizadas e a associá-las à boa realização da tarefa. [...] Trata-se [...] de levar o aluno a experimentar que ele pode influenciar os produtos desta atividade (GRANGEAT, 1999, p.156). 
Diante dessa necessidade de promover experiências metacognitivas aos alunos e de propor situações problemáticas que requeiram deles mais do que repetir procedimentos préestabelecidos pelo professor é que consideramos haver confluências entre a Modelagem Matemática e as práticas de monitoramento.

\section{Encaminhamento metodológico}

Para subsidiar nossas argumentações em relação ao monitoramento cognitivo em atividades de Modelagem planejamos e realizamos um curso intitulado Investigações de assuntos do cotidiano por meio da Matemática. O curso foi desenvolvido em uma universidade pública com alunos do segundo ano do curso técnico integrado em Informática (Ensino Médio) e alunos do primeiro semestre do curso de Licenciatura em Matemática.

O curso iniciou com 17 alunos com idades entre 16 e 40 anos. Nenhum dos alunos tinha experiência com atividades de Modelagem Matemática. Durante o desenvolvimento das atividades do curso, o professor pedia que os alunos se reunissem em grupos, embora não fizesse orientações nem em relação à quantidade de elementos nem em relação à sua composição. Percebeu-se, no entanto, que de todos os grupos, um deles permaneceu com os mesmos participantes em todos os encontros. Formado por cinco pessoas, quatro eram alunos do Ensino Médio e uma era aluna da Licenciatura em Matemática. Por esse motivo, esse foi o grupo considerado nas análises que apresentamos neste artigo. Esse grupo era composto por duas mulheres e três homens. (D) - inicial do nome - era uma aluna do curso de licenciatura e tinha 23 anos no início do curso. (A), de 16 anos, era aluna do ensino médio e estudava na mesma turma em que estudavam os três homens, R2 de 17 anos, R1 e R3 de 16 anos.

Os dados dessa pesquisa, no caso, os áudios das falas dos alunos no decorrer do desenvolvimento das atividades de Modelagem, os registros escritos produzidos nas resoluções e as anotações do diário de campo do pesquisador, foram coletados em cada um dos encontros do curso (duas horas semanais).

Estamos cientes da complexidade de analisar práticas de monitoramento dos alunos no desenvolvimento atividades de Modelagem, considerando serem elas processos mentais e, por isso, internos e passíveis de inferência a partir da observação de expressões e falas dos sujeitos. Assim, apresentamos reflexões acerca das práticas de monitoramento manifestadas pelos alunos diante das especificidades das atividades e à luz dos pressupostos teóricos.

Para isso, utilizamos como ponto de partida as dimensões apresentadas por TovarGálvez (2008) para a vertente processual da metacognição, ou seja, para o monitoramento: 
reflexão, administração e avaliação; bem como os elementos que compõem o monitoramento cognitivo segundo Flavell e Wellman (1977), já que a reflexão, a administração e a avaliação são dimensões que emergem na atividade de Modelagem Matemática na medida em que o sujeito as utiliza e põe em ação seus conhecimentos metacognitivos. Nesse contexto, consideramos nas análises a configuração do monitoramento cognitivo expressa na Figura 1.

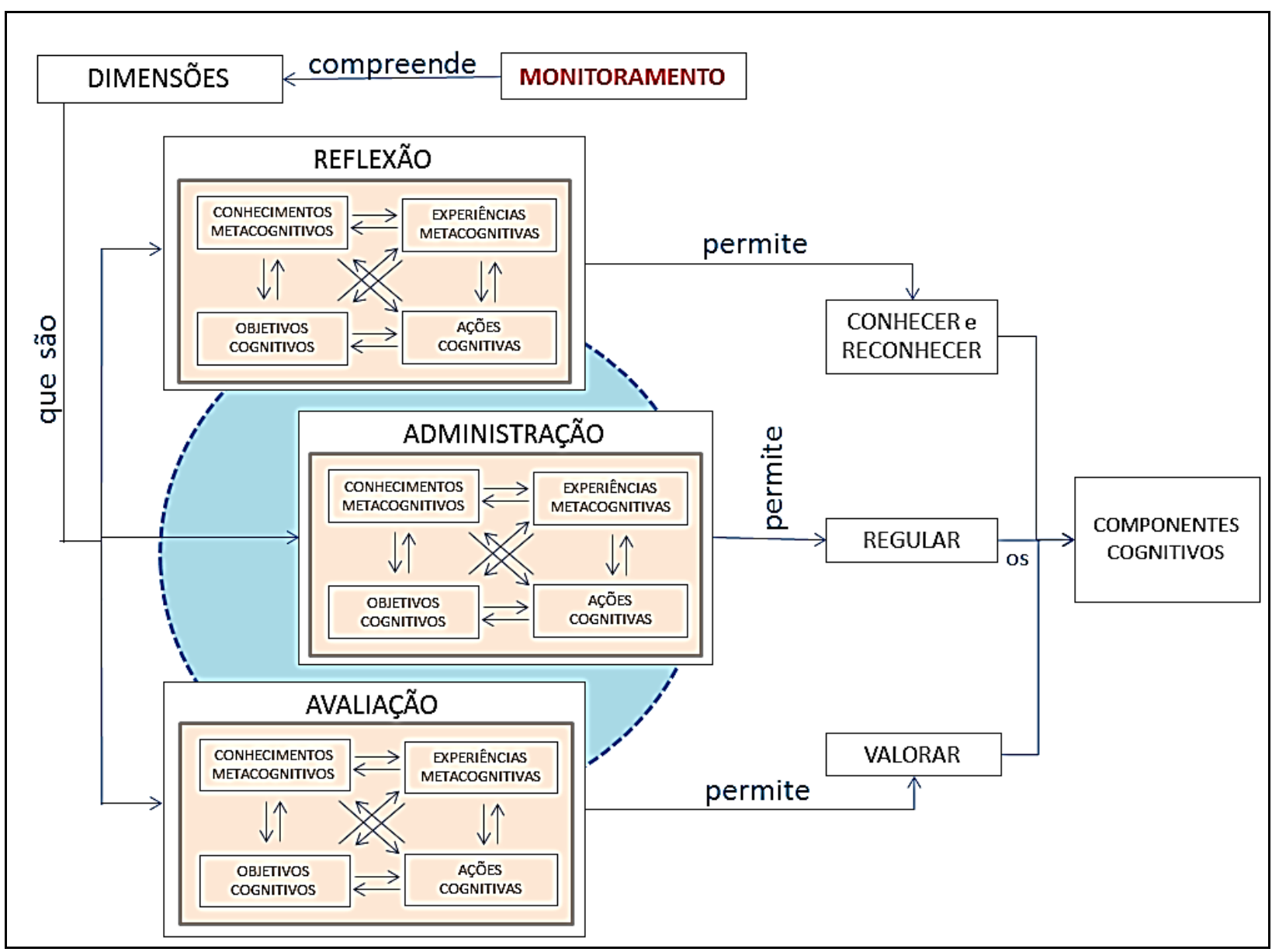

Figura 1 - Configuração do Monitoramento Cognitivo para a análise dos dados da pesquisa Fonte: elaborado pelo autor baseado em Tovar-Gálvez (2008), Flavell (1976) e Flavell e Wellman (1977)

Para além de analisar as ações dos alunos na atividade que descrevemos suscintamente na sequência, apresentamos também compreensões globais acerca do monitoramento cognitivo em Modelagem identificados no decorrer do curso como um todo.

\section{Práticas de Monitoramento Cognitivo em atividades de Modelagem Matemática}

Olhar para os registros escritos produzidos pelos alunos, não implica conhecer, necessariamente, os percursos e discussões empreendidos pelos alunos no desenvolvimento de uma atividade. É no momento dessas discussões que os alunos negociam significados, 
expõe ideias, intervém na resolução e manifestam ações cognitivas como as relacionadas ao monitoramento cognitivo, especificamente, refletem, administram e avaliam.

Por isso, nesse texto, apresentamos alguns dos Episódios que constituem discussões dos alunos acerca do desenvolvimento da atividade de Modelagem Matemática com o tema consumo de água na cidade de Toledo-PR. Selecionamos os Episódios que referem-se à elaboração do problema de investigação - fase inteiração da Modelagem -, do ajuste de curvas com vistas à construção de um modelo matemático para a população de Toledo - fase matematização - e do momento da interpretação dos resultados obtidos - fase interpretação.

Nessa atividade os alunos não elaboraram uma questão especificamente, mas escreveram sua intenção como segue:

Coletou-se dados referentes ao consumo de água nos últimos 11 anos junto à Sanepar e dados populacionais de Toledo segundo informações dos Censos 2000 e 2010 e Contagens de população de 1996 e 2007, para assim afirmar se o aumento notado no consumo de água nesse período de 2001 a 2011 se deve ao crescimento populacional ou ao aumento do consumo por habitante (Trabalho Escrito, 2011).

Os alunos pretendiam verificar se o crescimento no consumo de água em Toledo era decorrente apenas do crescimento populacional ou do aumento do consumo por habitante. No entanto, o que eles fizeram, de fato, foi verificar se tal aumento era causado exclusivamente pelo crescimento da população ou se essa população, além de aumentar em número, também havia consumido mais água.

O Episódio I tem como ponto de partida o interesse do professor em conhecer o tema (ou os temas) de trabalho escolhido pelos alunos.

$P$ (professor): Vocês já tem o modelo e vocês o consideraram válido pelo que percebi.

R1: Sim.

R1: A primeira ideia foi a $D$ que deu, um tema mais voltado pro consumo da água aqui em Toledo dai a gente ia pegar os dados do consumo da água e a gente poderia fazer uma previsão de gastos para daqui alguns anos baseado nesse consumo e também no aumento da população porque o gasto praticamente aumenta, todo ano aumentou, e daí pode comparar com o crescimento da população, já que tem dados de 2001 a 2011 e a gente poderia pegar dados do censo do município.

$[\ldots]$

R2: Todo ano aumentou, porque a tendência da cidade é crescer.

P: Podemos pensar... esse aumento da população está atrelado a quê?

R1: Ao crescimento da população.

P: Então seria interessante saber qual era a população em cada um desses anos em Toledo.

R1: Por isso que a gente pegou a de 2001, porque poderia pegar o censo porque o único jeito de saber é através do censo, ou tem alguma outra forma?

$P:$ É, tem o censo.

[...]

R2: Professor, e ele também me mostrou o consumo de janeiro desse ano, mas ele só me mostrou lá na tela...

P: Que legal, você já foi lá então [se referindo à Sanepar].

R2: Fui lá! 
P: Que legal!

R2: Daí dá pra ver 442, 458 e 463, e o desse ano foi 500 e pouco. Subiu muito, o desse ano acho que vai ser muito maior. Só que também faltou água esses dias aqui em Toledo, em vários locais da cidade.

R1: Isso tem a ver com a estação e período do ano.

A: É, dá pra ver aqui no meio, diminui bastante [se referindo ao consumo mensal em um ano - o meio seriam os meses do meio do ano, inverno em Toledo].

$[\ldots]$

R3: Quantos metros cúbicos têm por pessoa?

A: Talvez, ficaria até mais interessante.

R1: Quantos metros cúbicos têm por pessoa? Tem que dividir a água pela população, não é?

R3: Água pela população?

R1: Sim, de repente o número permanece praticamente o mesmo.

$P:$ Como assim?

R1: É que se der o mesmo, daí o aumento do consumo de água vai ser por causa do aumento da população só, entendeu? Se der mais, quer dizer que as pessoas tão usando mais (Fonte: Áudio dos encontros, 2011).

$\mathrm{Na}$ apresentação inicial feita por R1 é possível conhecer os encaminhamentos vislumbrados pelo grupo quando o aluno afirma "a gente poderia fazer uma previsão de gastos para daqui alguns anos baseado nesse consumo e também no aumento da população". É possível inferir que as experiências metacognitivas vivenciadas com Modelagem no âmbito do curso tenham constituído o conhecimento metacognitivo dos alunos em relação às especificidades das atividades de Modelagem no que tange à "maneira de lidar" com essas atividades, de modo que ao considerar o aumento no consumo de água na cidade, ideias sobre o que fazer (realizar uma previsão de consumo de água para os próximos anos) e o que considerar (dados de 2001 a 2011 sobre o consumo de água e dados sobre o censo populacional da cidade) surjam nas discussões dos alunos. A dimensão reflexão da metacognição presente no planejamento inicial dos alunos se dá, portanto, a partir do conhecimento metacognitivo dos alunos sobre as atividades de Modelagem.

Da inteiração com o tema surgiram duas possibilidades de trabalho: o estudo da dinâmica do consumo de água em Toledo no decorrer de um ano; a verificação se o aumento no consumo de água na cidade era consequência apenas do aumento da população ou se as pessoas, de fato, haviam consumido mais água.

O Episódio I indica que a primeira possibilidade surgiu quando R2 comenta que em janeiro de 2012 o consumo já havia sido maior que o consumo dos meses anteriores. R1 intervém de modo a explicar que esse aumento do consumo em janeiro deve-se às estações do ano, como quem considera que o consumo, a exemplo dos dados correspondentes a 2011, vai diminuir nos meses mais frios - "Isso tem a ver com a estação e o período do ano". Essa 
intervenção é compreendida por A que corrobora utilizando os dados sobre o consumo de água nos diferentes meses de 2011 - "É, dá pra ver aqui no meio-diminui bastante".

A outra possibilidade começa a ser delineada a partir da intervenção do aluno R3, quando pergunta "Quantos metros cúbicos tem por pessoa?". Essa pergunta muda os rumos da discussão sobre a dinâmica do consumo de água no decorrer de um ano, principalmente quando A reforça essa mediação - "Talvez ficaria até mais interessante". Essa fala da aluna A pode refletir seu entendimento das duas abordagens e na sua expectativa acerca das possíveis resoluções, o que implica em seu posicionamento a favor de uma delas.

Em relação à segunda possibilidade - investigar o consumo de água por pessoa na cidade - R1 compartilha da questão de R3 e sugere uma estratégia quando pergunta "Quantos metros cúbicos têm por pessoa? Tem que dividir a água pela população, não é?’. Ao ser questionado por R3 - “Água pela população?” - e pelo professor - "Como assim?” -, R1 apresenta sua sugestão: "Sim, de repente o número permanece praticamente o mesmo [...] É que se der o mesmo, daí o aumento do consumo de água vai ser por causa do aumento da população só, entendeu? Se der mais, quer dizer que as pessoas tão usando mais". A sugestão de R1, além de ser decisiva sobre o que fariam os alunos a partir de então, denota um conhecimento metacognitivo acerca das estratégias de resolução de um problema em Modelagem. Além de o aluno reconhecer nessa estratégia - dividir o consumo de água de um determinado ano pela população do respectivo ano - uma tradução da intenção manifestada por R3 em verificar quantos metros cúbicos de água haviam sido consumidos por pessoa, explicita, também, o que entende que podem significar os possíveis resultados, manifestando assim a dimensão reflexão da metacognição.

A obtenção de dados na Sanepar sobre o consumo de água na cidade nos anos de 2001 e 2011 levou os alunos a buscarem dados da população de Toledo-PR para o mesmo período. No entanto, no site do IBGE encontraram dados apenas para os anos em que houve algum tipo de contagem da população, 1996, 2001, 2007 e 2010, instaurando-se, a partir de então, a necessidade de estimar a população na cidade entre os anos de 2001 a 2011 não contemplados pelos censos. Nesse caso, o grupo decidiu construir um modelo matemático.

As discussões que seguem no Episódio II consideram os dados do IBGE (Tabela 1 e Figura 2). Os alunos discutem um possível ajuste para os dados. 


Tabela 1 - População em Toledo
\begin{tabular}{|c|c|}
\hline Ano & População \\
\hline 1996 & 90417 \\
\hline 2001 & 98200 \\
\hline 2007 & 109857 \\
\hline 2010 & 119313 \\
\hline
\end{tabular}

Fonte: Registro utilizado pelos alunos na atividade, 2011

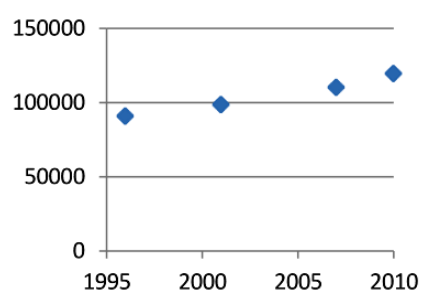

Figura 2 - População em Toledo, IBGE

Fonte: Registro utilizado pelos alunos na atividade, 2011

R1: Eu acho que vai ser uma linear.

R3: Vai ser uma linear mesmo.

RI: Não vai crescer muito de cada vez, porque uma exponencial cresceria e aqui não...

R2: Como é que a gente faz para saber se o crescimento é linear, é sempre o mesmo de um ano para o outro?

Rl: Hã?

R3: Boa pergunta!

$[\ldots]$

R3: Pega a régua. [risos]

R1: Tem que fazer a diferença? E faz a média depois?

R2: Faz pra ver.

[...]

R1: Não é só fazer a média deles?

R2: Não! Não é né... É a média das diferenças!

R3: Média das diferenças?

R1: É, porque vai ser o tanto que cresceu desse pra esse e desse pra esse... É? [...] Não!

R3: Porque vai achar.. diminuir esse por esse, esse por esse, esse por esse, certo?

R1: Sim

R3: E divide por 3.

R1: Por três? É pela quantidade de anos ou de diferenças?

R3: É pela quantidade de tempo que se passou entre um ano e outro.

R1: Vamos fazer.

[...] alunos fazem os cálculos. Em seguida, constroem diferentes ajustes utilizando o software livre Graphmática. Continuam o ajuste linear.

R3: Como que é uma reta mesmo? A equação?

RI: $b x+c$

R3: $O$ que a gente tem que fazer?

R1: $O$ c é referente a altura né, no eixo y.

R3: Hum. E quanto que é esse valor?

R1: Esse valor... seria o primeiro né?

R3: 90417 ?

Rl: É né, porque é quando o x é zero. E o b?

$[\ldots]$

R3: Boa pergunta!

R1: Eu lembro que a gente já fez isso.

[...]

R3: Não tem como usar os outros valores?

[...]

R3: E se substituir?

R1: Sim, sim, sim. Se substituir o x e o y vai ficar sobrando o b.

[...] RI começa a escrever.

R3: O que seria o b daí?

R1: $O$ b tem a ver com a inclinação da reta.

R3: Hã? (Fonte: Áudio dos encontros, 2011). 
As informações do Episódio II indicam que os alunos conversam sobre a possibilidade de realizar um ajuste linear para representar o aumento populacional de Toledo. Pensar em um ajuste linear foi uma ação cognitiva recorrente da visualização do gráfico construído pelos alunos no Excel (Figura 2). R1 até cogita a possibilidade de utilizar uma função exponencial, mas descarta a ideia já que pondera que o crescimento não seria tão acentuado: "Não vai crescer muito de cada vez, porque uma exponencial cresceria e aqui não...”. Isto remete à dimensão reflexiva da metacognição que, nesse caso, advém da análise conjunta do gráfico, da tabela, das opiniões dos alunos sobre como se daria o crescimento populacional, bem como de seus conhecimentos matemáticos sobre aspectos do crescimento exponencial e linear.

A dimensão administrativa da metacognição também figura nas transcrições desse Episódio. A primeira vez, quando R2 chama a atenção dos alunos para que pensem em uma maneira de verificar se o crescimento da população de um ano para outro era realmente linear, - "Como é que a gente faz para saber se o crescimento é linear, é sempre o mesmo de um ano para o outro?". A colocação de R2 denota um conhecimento sobre como proceder na situação, já que utiliza como sinônimo as expressões crescimento linear e crescimento é o mesmo de um ano para o outro, no entanto, o próprio aluno não se dá conta disso.

Somente depois de algum tempo os alunos decidem calcular a diferença de população entre dois dados da tabela e dividir o resultado pelo número de anos compreendidos entre um dado e outro. Esse raciocínio foi sendo elaborado aos poucos pelos alunos, de modo que R1 manifesta "Tem que fazer a diferença? E faz a média depois? [...] É, porque vai ser o tanto que cresceu desse pra esse e desse pra esse..." e R3 completa dizendo que a diferença deve ser dividida "pela quantidade de tempo que se passou entre um ano e outro" dentre os presentes na tabela - falas que remetem à reflexão sobre uma estratégia, sobre o como proceder nessa situação.

Os alunos realizaram os cálculos e decidiram considerar aproximadamente constante o aumento na população de Toledo entre um ano e outro, talvez mais influenciados pela representação gráfica do que pelos resultados numéricos. Mesmo porque, nesse momento da resolução, enquanto alguns alunos realizavam os cálculos, outros utilizavam o software livre Graphmática para plotar diferentes ajustes.

Para determinar uma expressão algébrica para descrever a população de Toledo em diferentes anos os alunos optaram por desenvolver um modelo sem o apoio do software. Nesse contexto é que R3 manifesta a dimensão administrativa da metacognição. Enquanto conversa com R1, R3 tenta relembrar a expressão de uma função do primeiro grau e a relação de seus parâmetros com o gráfico da função. 
O modo como R3 questionou o grupo (em especial, R1) funcionou como se estivesse questionando a si próprio, o que constitui uma possível prática de monitoramento cognitivo. Um sujeito que faz indagações desse tipo a aqueles com os quais resolve o problema, pode influenciar práticas de monitoramento em seus pares, dado que tais práticas parecem ser aprendidas nas interações que os sujeitos estabelecem entre si. R3 questiona como quem administra a resolução do grupo e como quem elabora as questões para pensar sobre elas. Em consequência, intervém de modo a influenciar R1 em relação a como proceder para encontrar o valor do parâmetro b na expressão $f(x)=b x+c$. R3 pergunta se "não tem como usar os outros valores?" para obter b e ainda sugere "e se substituir?" - conhecimentos que remetem ao conhecimento metacognitivo das estratégias de resolução.

É a partir das falas de R3 que R1, que antes havia dito "eu lembro que a gente já fez isso" - um conhecimento da variável pessoa do conhecimento metacognitivo -, recorda como proceder de modo a obter o valor de b na expressão do primeiro grau: "sim, sim, sim, se substituir o $x$ e o y vai ficar sobrando o $b$ ".

$\mathrm{Na}$ sequência das discussões apresentadas nesse Episódio, os alunos escolhem o último par ordenado da tabela $(2010 ; 119313)$ para obter o valor de b no modelo matemático referente ao crescimento populacional de Toledo. Justificam a escolha apenas no trabalho escrito: $O$ ano de 2010 também foi escolhido para que o valor de a [b na transcrição] fosse mais refinado, já que pequenas variações no crescimento populacional do município podem ter acontecido. Não é possível saber, no entanto, se os alunos utilizaram os diferentes pares ordenados de modo a optar pelo modelo que apresentasse melhor validação. $\mathrm{O}$ grupo obteve o modelo $f(a)=2064 . a+4029327$ como representativo da situação, em que $a$ representa o ano e $f(a)$ representa o número de habitantes em Toledo no ano $a$. Em seguida, calcularam a razão entre o consumo de água em certo ano e a população correspondente, obtendo:

Tabela 2 - Razão entre o consumo de água e o número de habitantes em Toledo

\begin{tabular}{c|c|c|c}
\hline Ano & População & Consumo de água $\left(\mathrm{m}^{3}\right)$ & Consumo de água $\left(\mathrm{m}^{3}\right) /$ habitante \\
\hline 2001 & 100737 & 3599822 & $\mathbf{3 5 , 7 3}$ \\
\hline 2002 & 102801 & 3749588 & $\mathbf{3 6 , 4 7}$ \\
\hline 2003 & 104865 & 3878301 & $\mathbf{3 6 , 9 8}$ \\
\hline 2004 & 106929 & 3994728 & $\mathbf{3 7 , 3 5}$ \\
\hline 2005 & 108993 & 4155683 & $\mathbf{3 8 , 1 2}$ \\
\hline 2006 & 111057 & 4318282 & $\mathbf{3 8 , 8 8}$ \\
\hline 2007 & 113121 & 4466858 & $\mathbf{3 9 , 4 8}$ \\
\hline 2008 & 115185 & 4627740 & $\mathbf{4 1 , 4 8}$ \\
\hline 2009 & 117249 & 4864255 & $\mathbf{4 2 , 4 6}$ \\
\hline 2010 & 119313 & 5066462 & $\mathbf{4 3 , 5 5}$ \\
\hline 2011 & 121377 & 5268782 & \\
\hline
\end{tabular}


As discussões dos alunos sobre o cálculo da referida razão e algumas conclusões advindas da sua utilização na interpretação da situação inicial constituem o Episódio III.

R1: Agora a gente tem que fazer uma previsão? A não... é quanto cada um...

R3: Faz uma divisão.

R1: O consumo pela população... né?

R3: Acrescenta uma linha [se referindo à linha para realizar a divisão no excel]. Acho que esse daí tem que fazer...

R1: Esse... dividido por esse.

[...]

R3: Tô curioso para saber o resultado.

R1: Tchãrãrãrã...

R3: Aumentou o consumo!

R1: Realmente, aumentou o consumo!

R3: Nossa!

R1: Mas a população também aumentou.

R3: Ah sim, sim, mas tipo... o consumo não foi tipo... o consumo não aumentou em relação à população. Entendi. Aumentou porque a população consumiu mais. Só o aumento da população não é o motivo para..

R1: O aumento no consumo de água, se você for ver, foi muito grande. Se você pensar no aumento por habitante, parece que não foi tão grande assim... Quer dizer, foi se a gente pensar de 2001 até 2011, dez anos depois as pessoas estão consumindo em média... quanto que dá?

R3: Quase 10

R1: 8 litros a mais!

R3: Litros? 8 mil metros quadrados, cúbicos

R1: Estão consumindo 8 metros cúbicos a mais por ano.

$[\ldots]$

R1: Será que se a gente fizesse por dia não ficaria mais real, porque às vezes a gente não sabe quanto por dia.

R3: Só que não dá pra fazer por dia porque no verão se gasta mais.

R1: Ah é verdade, mas dá pra fazer uma média pra ter uma noção, tipo, por mais que tenha estação que você não bebe e nem toma banho direito... [risos]

$[\ldots]$

R3: É 21 litros, 22 litros a mais por dia.

R1: Geeeennnnte!

[...]

R3: $O$ que são 22 litros?

[...]

R3: Muita água [risos]

R1: [risos] são quase 3 daqueles baldinhos pequenos, aqueles baldinhos de 1,99. (Fonte: Áudio dos encontros, 2011).

Já no início das falas apresentadas no Episódio III os alunos manifestam a dimensão administrativa da metacognição quando, uma vez obtido o modelo matemático para estimar a população em Toledo, buscam pensar na próxima atividade a desenvolver. R1 pergunta "Agora a gente tem que fazer uma previsão?" - o que remete às experiências anteriores com atividades de Modelagem Matemática - e ele mesmo completa, como quem monitora a atividade e recorda o planejamento inicial: “A não... é quanto cada um...”, se referindo ao consumo de água por pessoa em Toledo. 
$\mathrm{Na}$ avaliação realizada, os alunos concluíram que o aumento no consumo de água da cidade advém tanto do aumento da população quanto do aumento no consumo por pessoa. Nesse sentido, R1 atenta para o fato de que o aumento total no consumo de água na cidade parece ser muito grande, enquanto o aumento por habitante parece não ter sido tão acentuado, principalmente ao considerar uma medida não tão usual para eles: 8 metros cúbicos no ano.

Depois de alguns encontros e muitas discussões, os alunos concluíram:

É notável o crescimento no consumo de água por habitante. A variação de consumo é de aproximadamente 7,82 $\mathrm{m}^{3}$, ou seja, 7820 litros. Assim, cada habitante de Toledo em 2011, consumiu 7820 litros a mais de água do que os habitantes de Toledo em 2001. Ou ainda, cada habitante de Toledo em 2011 consumiu 21,42 litros de água a mais diariamente do que em 2001 (Trabalho Escrito, 2011).

Nesse momento da resolução os alunos já haviam cumprido o propósito inicial. No entanto, surpresos diante do aumento na quantidade diária de água consumida por habitante, decidiram construir um modelo que pudesse descrever a quantidade de metros cúbicos de água consumidos por habitante no decorrer dos próximos anos.

\title{
6 Discussão
}

Os dados dessa pesquisa levam-nos a inferir que quanto mais os sujeitos realizam as atividades de Modelagem, mais familiarizados ficam em relação a essas atividades e mais empreendem práticas de monitoramento nelas. Inferimos que isso se dá porque as práticas de monitoramento cognitivo são, assim como os conceitos e procedimentos, aprendidas por intermédio de mediações nas interações sociais, principalmente no momento em que falas medeiam a ação do outro e a formação da consciência. Segundo Fávero (2005):

\begin{abstract}
A cooperação social na atividade realiza-se por meio de instrumentos, dentre os quais os signos verbais desempenham um papel primordial; é pela interiorização progressiva desses instrumentos de cooperação que se constrói o pensamento consciente, que regula as outras funções psíquicas (FÁVERO, 2005, p.187).
\end{abstract}

Uma prática de monitoramento utilizada pelo professor quando intervinha nas discussões do grupo e que passou a ser utilizada pelos alunos no decorrer do curso de Modelagem e que denota que práticas de monitoramento são aprendidas, é o ato de interrogarse, o fazer perguntas a si mesmos (e ao grupo), como forma de pensar sobre as questões.

Nesse sentido, atentamos para a importância do trabalho em grupo nas atividades de Modelagem no que tange ao desenvolvimento de práticas de monitoramento. O trabalho em grupo instaura, ainda, a possibilidade de um monitoramento que embora tenha origem individual, torna-se coletivo na medida em que adquire configurações peculiares do grupo, 
exerce influência no desenvolvimento das atividades de Modelagem e medeia as aprendizagens dos diferentes sujeitos. Trata-se, portanto, de encarar a Modelagem segundo uma perspectiva metacognitiva, em que as práticas de monitoramento são empreendidas coletivamente, o que nos leva a denominar tais práticas, nesse contexto e dada essa especificidade, de metacognição social.

Assim, ao mesmo tempo em que as práticas de monitoramento são inicialmente individuais, por serem suscitadas por um dos sujeitos, passam a ser empreendidas coletivamente na medida em que os sujeitos manifestam essas práticas aos colegas do grupo, que as discutem. Elas, as práticas de monitoramento, são constituídas, assim, nas experiências dos sujeitos, nas interações, sendo, portanto, na realidade, práticas de monitoramento sociais.

$\mathrm{O}$ fato de as atividades de Modelagem serem atividades abertas e permitirem múltiplas possibilidades de resolução, tanto no que diz respeito à escolha do tema, à elaboração de uma questão, quanto no que se refere aos conteúdos e estratégias considerados no desenvolvimento da atividade, pode ser entendido como característica das atividades de Modelagem que promovem o monitoramento cognitivo referente à dimensão reflexiva. As atividades de Modelagem são desenvolvidas pelos alunos com certa autonomia e, geralmente, não é possível aos alunos recorrerem à estratégia siga o exemplo dado pelo professor, o que desencadeia discussões entre os alunos em relação ao que fazer para investigar certa situação.

É visando planejar ações que possibilitem a investigação, que os alunos, na dinâmica de um grupo, recorrem aos seus conhecimentos prévios para construir um plano de ação não mais individual, mas coletivo. As reflexões que emergem nesse contexto levam os alunos a revisitarem conceitos já aprendidos, ressignificando-os a partir das especificidades da situação investigada e da mediação realizada pelos outros componentes do grupo, bem como a internalizar outros conceitos conforme esses emergem nas discussões.

Outro elemento das atividades de Modelagem que suscitou reflexões nos alunos, também relacionado às diferentes possibilidades de resolução, é a importância de se utilizar diferentes representações para poder pensar o problema, como quando decidem converter metros cúbicos em litros na interpretação dos resultados obtidos na situação do consumo de água em Toledo, com vistas a compreender a solução encontrada na atividade.

Por maior que seja o tempo de duração de uma atividade de Modelagem Matemática ou por mais que a atividade possa ser realizada em fases, a unicidade da atividade é outro elemento que suscita o monitoramento cognitivo relacionado à reflexão. A unicidade, nesse caso, refere-se à necessidade de considerar (e recorrer) no desenvolvimento da atividade e nas diferentes fases da Modelagem, às informações e aos conhecimentos da situação como um 
todo. Ou seja, mesmo que existam diferentes tarefas na atividade de Modelagem tais como elaborar uma questão, validar uma informação, resolver um sistema de equações, interpretar um resultado, construir um gráfico, ainda assim, há de se manter uma compreensão do todo e utilizar essa compreensão no desenvolvimento da atividade. As reflexões que emergem devido à unicidade das atividades de Modelagem desencadeiam a própria unicidade, ou seja, desencadeiam a prática constante de analisar o desenvolvimento da atividade considerando-a em sua totalidade.

Embora a administração tenha acontecido em todas as atividades de Modelagem realizadas no âmbito do curso, nas primeiras era uma dimensão muitas vezes ensejada pelo professor e não pelos alunos. Na medida em que as atividades eram realizadas e compreensões acerca das atividades de Modelagem eram construídas, a administração tornase atividade predominantemente desencadeada pelos alunos.

As práticas de monitoramento relacionadas à administração nas atividades de Modelagem emergiram quando os alunos visavam verificar se procedimentos utilizados em atividades anteriores de Modelagem poderiam ser utilizados na nova atividade; decidir entre mudar os rumos da resolução ou manter o planejamento inicial; voltar ao problema, chamando a atenção do grupo para as discussões, quando discussões paralelas tomavam muito tempo; encontrar um encaminhamento que possibilitasse confirmar ou não uma estimativa, verificar a viabilidade ou não de uma ideia e/ou relembrar conceitos já estudados; avaliar resultados estranhos em relação às informações da situação inicial ou decidir por um melhor ajuste e; realizar ajustes e simplificações no desenvolvimento das atividades de Modelagem.

Administrar o desenvolvimento de uma atividade de Modelagem já é, por si só, uma estratégia de resolução. Se por um lado essa estratégia contribui para o que denominamos unicidade das atividades de Modelagem Matemática, por outro, é via a administração que práticas de monitoramento relacionadas às dimensões reflexão e avaliação são provocadas e empreendidas pelos sujeitos nas atividades.

A avaliação, portanto, era praticada quando os alunos tinham a intenção de analisar e validar a própria ideia, a declaração de outro ou avaliar um pressuposto; validar resultados considerando o contexto inicial; ou comparar resultados de modo a tomar decisões. Essa dimensão metacognitiva, a avaliação, parece fortalecer, portanto, o planejamento de encaminhamentos a considerar no desenvolvimento de atividades de Modelagem.

Diante do exposto e com vistas a evidenciar as manifestações dos alunos no que se refere à intenção desse artigo - identificar as formas de monitoramento cognitivo expressas pelos alunos durante a realização de atividades de Modelagem Matemática e caracterizar 
elementos das atividades de Modelagem Matemática que promoveram o monitoramento cognitivo - apresentamos o seguinte quadro (Quadro 1).

\begin{tabular}{|c|c|c|}
\hline & $\begin{array}{l}\text { Quais formas de monitoramento cognitivo são } \\
\text { expressas pelos alunos durante a realização de } \\
\text { atividades de Modelagem Matemática? }\end{array}$ & $\begin{array}{c}\text { Quais elementos das atividades de Modelagem } \\
\text { Matemática promovem o monitoramento cognitivo? }\end{array}$ \\
\hline & $\begin{array}{l}\text { Em relação à dimensão reflexiva, os alunos realizaram o } \\
\text { monitoramento cognitivo ao: } \\
\text { mudarem a representação em que é dada a solução do } \\
\text { problema, de modo a tornar compreensível a solução } \\
\text { construírem uma representação gráfica a partir de } \\
\text { dados iniciais para pensar sobre uma delimitação de } \\
\text { encaminhamento de resolução e de quais conceitos } \\
\text { matemáticos considerar; } \\
\text { estimarem resultados e planejar encaminhamentos; } \\
\text { simplificarem informações na situação inicial; } \\
\text { relacionarem a Matemática e a situação investigada; } \\
\text { refletirem acerca da situação extra matemática; } \\
\text { refletirem acerca dos conteúdos matemáticos } \\
\text { suscitados nas atividades. }\end{array}$ & $\begin{array}{l}\text { O monitoramento cognitivo em sua dimensão reflexiva } \\
\text { foi suscitado nas atividades de Modelagem devido a } \\
\text { essas: } \\
\text { serem abertas e com múltiplas possibilidades de } \\
\text { encaminhamento; } \\
\text { requererem dos alunos o reconhecimento e a } \\
\text { utilização de conhecimentos prévios; } \\
\text { serem realizadas considerando a unicidade da } \\
\text { atividade de Modelagem; } \\
\text { requererem o uso de diferentes representações como } \\
\text { estratégia para pensar o problema. }\end{array}$ \\
\hline & $\begin{array}{l}\text { Em relação à dimensão administrativa, os alunos realizaram } \\
\text { o monitoramento cognitivo ao: } \\
\text { decidirem entre mudar os rumos da resolução ou } \\
\text { manter o planejamento inicial; } \\
\text { voltarem ao problema, chamando a atenção do grupo } \\
\text { para as discussões; } \\
\text { encontrarem um encaminhamento que possibilitasse } \\
\text { confirmar ou não uma estimativa, verificar a } \\
\text { viabilidade ou não de uma ideia e/ou relembrar } \\
\text { conceitos já estudados; "estranhos" em relação às } \\
\text { avaliarem resultados "aç no } \\
\text { informações da situação inicial; } \\
\text { realizarem ajustes e simplificações no } \\
\text { desenvolvimento das atividades de Modelagem } \\
\text { Matemática. }\end{array}$ & $\begin{array}{l}\text { O monitoramento cognitivo em sua dimensão } \\
\text { administrativa foi suscitado nas atividades de Modelagem } \\
\text { devido a essas: } \\
\text { requererem a elaboração de questões para investigar } \\
\text { relacionadas à situação inicial; } \\
\text { serem realizadas considerando a unicidade da } \\
\text { atividade de Modelagem; } \\
\text { serem realizadas no âmbito de um grupo; } \\
\text { serem abertas e com múltiplas possibilidades de } \\
\text { encaminhamento. }\end{array}$ \\
\hline 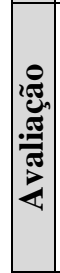 & $\begin{array}{l}\text { Em relação à dimensão avaliativa, os alunos realizaram o } \\
\text { monitoramento cognitivo ao: } \\
\text { analisarem e validarem a própria ideia ou a declaração } \\
\text { de outro; } \\
\text { validarem resultados considerando o contexto da } \\
\text { situação inicial; } \\
\text { compararem resultados de modo a tomar decisões. }\end{array}$ & $\begin{array}{l}\text { O monitoramento cognitivo em sua dimensão avaliativa } \\
\text { foi suscitado nas atividades de Modelagem devido a } \\
\text { essas: } \\
\text { - serem realizadas em essencialmente no âmbito de um } \\
\text { grupo em que uns intervém nas ações e ideias dos } \\
\text { outros; } \\
\text { - requererem a interpretação e validação de resultados. }\end{array}$ \\
\hline
\end{tabular}

Quadro 1 - O que evidenciam ou revelam as atividades de Modelagem em relação ao monitoramento cognitivo Fonte: Do autor (2013)

\section{Referências}

ALMEIDA, L. W. de; SILVA, K. P. da; VERTUAN, R. E. Modelagem Matemática na Educação Básica. São Paulo: Contexto, 2012.

\section{ANASTÁCIO, M. Q. A. Considerações sobre a Modelagem Matemática e a educação}

matemática. 1990. 100f. Dissertação (Mestrado em Educação Matemática) - Universidade Estadual Paulista, Rio Claro, 1990.

BEAN, D. W. As premissas e os pressupostos na construção conceitual de modelos matemáticos. In: Sipem - Seminário Internacional de Pesquisa em Educação Matemática, 5., 2012, Petrópolis. Anais..., Petrópolis: Sbem, 2012. p.1-22. CD-ROM. 
BROWN, J.; EDWARDS, I. Modelling tasks: insights into mathematical understanding. In: KAISER, G.; BLUM, W.; FERRI, Rita B.; STILLMAN, G. (Org.). Trends in teaching and learning of mathematical modeling. New York: Springer, 2011. p.187-197.

CIFUENTES, J. C.; NEGRELLI, L. G. O processo de Modelagem Matemática e a Discretização de Modelos Contínuos como Recurso de Criação Didática. In: ALMEIDA, L. M. W.; ARAÚJO, J. de L.; BISOGNIN, E. (Org.). Práticas de Modelagem Matemática na Educação Matemática. Londrina: Eduel, 2011. p.123-140.

COHORS-FRESENBORG, E. et al. The role of metacognitive monitoring in explaining differences in mathematics achievement. ZDM - The international journal on Mathematics Education, Monterrey, v.42, n.2, p.231-244, 2010.

D’AMORE, B. Elementos de didática da Matemática. Tradução de M. C. Bonomi. São Paulo: Livraria da Física, 2007.

DOLY, A. M. Metacognição e mediação na escola. In: GRANGEAT, M. (Coord.). A Metacognição, um Apoio ao Trabalho dos Alunos. Tradução de T. M. Estrela. Porto: Porto Editora, 1999. p.17-59.

FÁVERO, M. H. Psicologia e conhecimento: subsídios da psicologia do desenvolvimento para a análise de ensinar e aprender. Brasília: Editora Universidade de Brasília, 2005.

FERRAZ, A. P. do C. M.; BELHOT, R. V. Taxionomia de Bloom: revisão teórica e apresentação das adequações do instrumento para definição de objetivos instrucionais. Gestão e Produção, São Carlos, v.17, n.2, p.421-431, 2010.

FLAVELL, J. H. Metacognition and cognitive monitoring: a new area of cognitive - developmental inquiry. American Psychologist, Washington, DC, v.34, n. ${ }^{\circ} 10$, p.906-911, 1979.

FLAVELL, J. H. Metacognitive aspects of problem-solving. In: RESNICK, L. B. (Ed.). The nature of intelligence. Hillsdale: Lawrence Erlbaum Associates, 1976. p.231-236.

FLAVELL, J. H.; WELLMAN, H. M. Metamemory. In: KAIL, R.; HAGEN, J. W. (Ed.).

Perspectives on the development of memory and cognition. Hillsdale: Erlbaum, 1977. p.3-33.

GONZÁLEZ, F. E. Metacognición y aprendizaje estratégico. Integra Educativo, Revista de Integración Educativa, La Paz, v.2, n. ${ }^{\circ 2}$, p.127-136, 2009.

GONZÁLEZ, F. E. Metacognición y tareas intelectualmente exigentes. Zetetiké, v.6, p.59-70, 1998.

GRANGEAT, M. A metacognição, uma chave para aprendizagens escolares bem sucedidas.

In:__ (Coord.). A Metacognição, um Apoio ao Trabalho dos Alunos. Tradução de T. M. Estrela. Porto: Porto Editora, 1999. p.151-171.

LANZ, M. Z. Hacia la comprensión del aprendizaje autorregulado. In: . (Org.). El aprendizaje autorregulado: enseñar a aprender en diferentes entornos educativos. Buenos Aires: Noveduc, 2006. P.08-21.

MEYER, J. F. C. A.; CALDEIRA, A. D.; MALHEIROS, A. P. S. Modelagem em Educação Matemática. Belo Horizonte: Autêntica, 2011.

TOVAR-GÁLVEZ, J. C. Modelo metacognitivo como integrador de estrategias de enseñanza y estratégias de aprendizaje de las ciências, y su relación con las competências. Revista

Iberoamericana de Educación, Madrid, n. ${ }^{\circ}$ 46/7, p.1-9, jul, 2008. 
Submetido em Junho de 2015. Aprovado em Outubro de 2015. 